Disponível em

http://www.anpad.org.br/rac

RAC, Curitiba, v. 14, n. 2, art. 8,

pp. 333-352, Mar./Abr. 2010

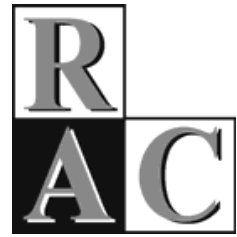

\title{
Fatores Condicionantes de Inadimplência em Processos de Concessão de Crédito a Micro e Pequenas Empresas do Estado de Minas Gerais
}

\section{Determining Factors of the Default in Processes of Credit Concession to Micro and Small Businesses in the State of Minas Gerais}

\begin{abstract}
Marcos Antônio de Camargos * Doutor em Administração pelo CEPEAD/UFMG. Professor Faculdade Novos Horizontes, Belo Horizonte/MG, Brasil.

Mirela Castro Santos Camargos Doutora em Demografia pelo CEDEPLAR/UFMG. Gestora de ensino e pesquisa do Centro de Estudos e Políticas Públicas da FJP, Belo Horizonte/MG, Brasil.

Flávio Wagner Silva Graduando em Administração pela UNI-BH, Belo Horizonte/MG, Brasil.

Fabiana Soares dos Santos Graduando em Administração pela UNI-BH, Belo Horizonte/MG, Brasil.

Paulo Junio Rodrigues Graduando em Administração pela UNI-BH, Belo Horizonte/MG, Brasil.
\end{abstract}

\footnotetext{
* Endereço: Marcos Antônio de Camargos

Rua Alvarenga Peixoto, 1270, sala C1 T05, B. Santo Agostinho, Belo Horizonte/MG, 30180-121. E-mail: marcos.camargos@unihorizontes.br
}

Copyright (C) 2010 RAC. Todos os direitos, inclusive de tradução, são reservados. É permitido citar parte de artigos sem autorização prévia desde que seja identificada a fonte. 


\title{
RESUMO
}

O objetivo deste artigo é identificar e analisar os fatores condicionantes da inadimplência nos processos de financiamentos concedidos pelo BDMG no Programa GERAMINAS entre junho de 1997 e janeiro de 2006. Utilizou-se do universo de dados do período, constituído de 25.616 processos de 17.743 micro e pequenas empresas. Trata-se de uma pesquisa quantitativa, na qual foi utilizado o Modelo de Regressão Logística Binária. Foi constatado que os seguintes fatores atuam como condicionantes da inadimplência: 1) ter maior porte (pequena $\mathrm{x}$ micro); 2) atuar em um mercado com baixas oportunidades; 3) ser do setor industrial, quando comparado com o comercial e de serviços; 4) pouco tempo de atividade da empresa; 5) nível de informatização intermediário e gerenciada por sócios possuidores do diploma de segundo grau; 6) valor dos bens do avalista; 7) experiência do sócio no negócio; 8) uso dos recursos obtidos no financiamento como capital de giro; 9) valor do faturamento da empresa. A maioria dos resultados obtidos encontra suporte na literatura, exceto quanto aos fatores 5, 8 e 9, que a contrariam, instigando novas pesquisas. Gerencialmente, os fatores encontrados nesta pesquisa poderiam ser utilizados para traçar políticas ou estratégias por parte da instituição pesquisada e outras correlatas na redução ou controle do seu nível inadimplência.

Palavras-chave: crédito; inadimplência; micro e pequenas empresas; programa GERAMINAS.

\begin{abstract}
The objective of this paper is to identify and analyze the factors that lead to the default in the processes of financings granted by the BDMG in the GERAMINAS Program between June of 1997 and January of 2006. The data of the period were used, consisting of 25,616 processes pertaining to the 17,743 micro and small businesses. It is a quantitative study, which made use of the Model of Binary Logistic Regression to analyse the data. The results have shown the following determinants factors of the default: 1 . the size of company (small $x$ micro businesses); 2. market with low opportunities; 3 . to be of the industrial sector, when compared with the commerce and of services; 4 . company has been operational for a short time; 5. intermediate level of informatization and managed by partners possessing only high school diplomas; 6 . value of the goods of the guarantor; 7. experience of the business partners; 8. use of the resources obtained in the financing as working capital; 9. value of the invoicing of the company. The majority of these findings are supported by the literature, except factors 5, 8 and 9, that oppose it, which menas a need for further studies. In terms of management, the findings of this study could be used to form policies or strategies for the institution under study, or similar institutions, in order to reduce or control their levels of default.
\end{abstract}

Key words: credit; default; mícro and small businesses; GERAMINAS program. 


\section{INTRODUÇÃO}

A crescente integração de economias e mercados financeiros, associada ao aumento da competitividade internacional, tem exigido maior flexibilidade e agilidade por parte das empresas (Santos, 1995), fazendo com que ocorra uma fragmentação e especialização das grandes corporações em unidades menores, deixando de realizar muitas das atividades que não se relacionam diretamente com suas competências essenciais, core business (Naisbitt, 1994). Essas alterações levam ao surgimento de oportunidades de negócios que passam a ser exploradas pelas micro e pequenas empresas [MPE’s] que, desenvolvendo, muitas vezes, atividades terceirizadas, são responsáveis por fatia cada vez maior do Produto Interno Bruto do País.

Nesse cenário as MPE’s se apresentam como alternativa de produção viável, ao serem dotadas de características peculiares, que facilitam seu surgimento e sobrevivência: 1) relativa facilidade de constituição e entrada no mercado; 2) não se exigem grandes volumes de capital inicial; 3) registros e demais trâmites burocráticos de abertura cada vez mais facilitados por órgãos governamentais; 4) flexibilidade de gestão e produtiva; 5) baixas exigências legais e comerciais, quando comparadas a uma sociedade anônima, dentre outras. Mas se por um lado apresentam essas vantagens, por outro apresentam inúmeras desvantagens ou problemas latentes que dificultam principalmente sua sobrevivência e crescimento, tais como: 1) montante de recursos inicial suficiente para a abertura da empresa (para investimentos na produção, como máquinas, equipamentos, tecnologia; para compra de material e manutenção dos estoques); 2) gestão amadora, baseada apenas no empirismo e em experiências anteriores, o que compromete o seu crescimento e desenvolvimento; 3) falta de visão de negócios; 4) ausência de um planejamento estratégico de longo prazo norteador das ações e diretrizes da empresa; 5) elevado custo de capital associado ao risco do negócio, pois o maior risco com que são vistas faz com que as instituições financeiras exijam delas taxas de juros mais elevadas nos empréstimos; e 6) acesso ao crédito, tanto de curto, quanto de longo prazo, dificultado por exigências e condições inibidoras: foco de discussão nesta pesquisa.

Apesar de possuir um sistema financeiro sólido, com bancos privados nacionais de classe mundial altamente rentáveis, o volume de crédito concedido ao financiamento das atividades produtivas é ainda muito aquém do necessário, isso sem mencionar as elevadas taxas de juros e de spread bancário praticados na economia brasileira. Quando se compara a oferta de crédito ao Produto Interno Bruto [PIB] no Brasil observa-se que a taxa brasileira se mostra muito inferior ao normalmente fornecido em outros países, sendo de 52\% do PIB, comparados com 161\% nos Estados Unidos e 75\% no Chile (Sachs, 2003).

A oferta de crédito às MPE's se reveste de importância fundamental na perspectiva da representatividade econômica e da geração de postos de trabalho que elas têm na economia brasileira. Ademais, qualquer instituição financeira mantém uma política de crédito e cobrança bem delimitada, na qual são exigidas várias informações socioeconômicas sobre a empresa e sobre os empresários solicitantes, visando minimizar o risco de default, risco de inadimplência. No atual cenário, estudos que buscam identificar fatores condicionantes da inadimplência na concessão de crédito ganham relevância, tendo em vista os desdobramentos da crise crédito iniciada nos Estados Unidos e disseminada para as demais economias do mundo.

Dessa forma, estudos no Brasil que tenham por objeto as MPE’s são relevantes na medida em que a maioria dos estudos existentes tem como foco as grandes corporações, além do fato da importância que esse segmento desempenha para a economia. Ademais, é oportuno ressaltar o empenho que o Banco de Desenvolvimento de Minas Gerais [BDMG] tem mostrado na concessão de crédito para MPE's das diferentes regiões do Estado, ao ser a instituição mais atuante nesse tipo de serviço financeiro. Em âmbito institucional, destaca-se que, no período de 1997 a 2006, o GERAMINAS foi um dos seus programas de fomento mais importantes, abrangendo todo o Estado, fomentando as atividades de micro e pequenos empreendimentos legalmente constituídos. 
Inserido na discussão do controle da inadimplência na concessão de crédito pequenos empreendimentos, o objetivo deste artigo é identificar e analisar os fatores condicionantes da inadimplência nos processos de financiamentos concedidos pelo BDMG no âmbito do programa GERAMINAS. Ou seja, buscou-se aferir a influência exercida por variáveis de natureza qualitativa (características socioeconômicas de empresários, avalistas e MPE’s) no cumprimento das obrigações do financiamento. Para isso foram analisados dados de 25.616 processos de financiamento, concedidos entre junho de 1997 e janeiro de 2006. Na seqüência, é apresentado o quadro teórico de referência, seguido dos procedimentos metodológicos e análise e discussão dos resultados nas seções 2, 3 e 4, respectivamente. Encerra-se com as conclusões e considerações finais na seção 5, seguida das referências.

\section{REFERENCIAL TEÓRICO}

Conforme salientam Casarotto e Pires (1998), um problema crucial para as pequenas empresas brasileiras é o acesso ao crédito, especialmente de longo prazo, no qual as operações se dão morosamente, cabendo ao agente financeiro arcar com um custo operacional elevado. Baumgartner (2004) acrescenta que no sistema bancário, exceto os bancos de desenvolvimento, o pequeno empresário é obrigado a competir na mesma faixa de crédito das grandes empresas, sujeitando-se a critérios de seletividade e reciprocidade a elas concedidos na obtenção de financiamentos.

O crédito pode ser definido pela cessão temporária de recursos a terceiros, mediante remuneração (juros) cobrada ao devedor pelo seu uso, que pode ser concedido por vários tipos de empresas e para uma variada gama de finalidades, com destaque para o segmento bancário, que atua como agente intermediador das captações e aplicações de recursos na economia, sendo regulado por normas estabelecidas pelas autoridades monetárias. Para Caouette, Altman e Narayanan (1998), inerente ao crédito existe uma expectativa de se receber o montante emprestado, acrescido dos juros, em prazo definido. Assim, o risco de crédito é a possibilidade de que esta expectativa não se cumpra, o que, se acontecer, torna o devedor um inadimplente, risco de default.

O crescimento econômico em nível mundial e, conseqüentemente, em nível nacional, não se dá de maneira linear no tempo, mas em ciclos de baixo crescimento (crises) e de elevado crescimento (booms), principalmente dos chamados ativos financeiros ou valores mobiliários. Nesse último cenário, o acesso ao crédito é facilitado pela sua grande disponibilidade na economia e pela competição entre as instituições financeiras que, no afã de atingir metas de intermediação financeira e de aumentar sua carteira de clientes, reduz o nível de restrições ou exigências para a concessão do crédito. Isso ocorre porque, nesses períodos, a inadimplência reduz e o cumprimento quase integral dos contratos induz o sistema bancário a subavaliar os riscos, concedendo créditos com grande facilidade. Essa situação, entretanto, se inverte em épocas de crise, na qual há escassez de recursos na economia e aumento dos níveis de inadimplência, o que leva o sistema bancário a aumentar as restrições e o nível de exigência, bem como a superestimar os riscos e reduzir a quase nada a concessão de novos empréstimos.

Segundo Douat (1994) e Schrickel (1997), a atividade de crédito implica risco significativo para as instituições financeiras, pois se trata de uma modalidade de risco que está presente em qualquer atividade comercial, caracterizada pela probabilidade de não recebimento dos recursos emprestados. Na gestão desse risco, as instituições financeiras desenvolveram vasto aparato de técnicas, visando minimizar suas perdas. Essas técnicas que vão desde o treinamento de especialistas, até o uso de modelagens estatísticas que lhe conferiram maior robustez e eficácia na análise dos clientes (Caouette et al., 1998). O avanço dessas técnicas foi fortemente influenciado por governos e por órgãos de supervisão bancária, tendo em vista a importância da concessão e crédito para o desenvolvimento de determinados segmentos da economia, em especial o das MPE's. 
Para Minussi, Damacena e Ness (2001), a atividade de concessão de crédito é fortemente influenciada pelas condições macroeconômicas do país e pelas políticas governamentais, sendo, assim, caracterizada por movimentos cíclicos, flutuando entre um conservadorismo defensivo até uma agressividade responsável. Os sistemas de crédito são normalmente resultantes de uma camada de atitudes, respostas e padrões comportamentais que derivam do nível estratégico organizacional e, muitas vezes, do principal executivo responsável pela área. A filosofia da organização, sua tradição e os padrões existentes são os fatores adicionais incorporados.

Conforme pesquisas desenvolvidas pelo Serviço Brasileiro de Apoio às Micro e Pequenas Empresas [Sebrae], o crédito é fator determinante para o desempenho econômico-financeiro das MPE's. Em pesquisa realizada em 2000, constatou-se que existe uma inadequação do crédito para esse segmento, sinalizando que as principais dificuldades para obtenção de financiamento são a burocracia elevada (59\%) e juros elevados (40,7\%). Em complemento a isso, conforme destacam Almeida e Ross (2000), existem recursos financeiros disponíveis em várias instituições, mas o custo é alto para as empresas desse segmento, pois há percepção de risco elevado por parte das instituições financeiras. Para Shapero e Sokol (1982) o desenvolvimento de políticas voltadas para a promoção do empreendedorismo deve ser precedido pela construção de um sistema de apoio financeiro, freqüentemente mais importante que a própria expectativa de sucesso do negócio.

No que se refere às dificuldades encontradas pelas pequenas e micro empresas na obtenção de financiamento, Almeida e Ross (2000) destacam que a principal seria a não diferenciação na análise de crédito das MPE's e grandes empresas, o que praticamente impossibilita essa análise, porque, na maioria das vezes, os demonstrativos das MPE’s não são confiáveis. Esses autores salientam também que os instrumentos utilizados para decisão e análise de crédito pelos diversos bancos são praticamente os mesmos: 1) balanços patrimoniais (quando existem); 2) garantias reais; 3) feeling de analistas; 4) consultas à Centralização do Serviço de Bancos S.A. [Serasa]; 5) e ao Banco Central do Brasil. Ou seja, os bancos se utilizam da análise denominada de fundamentalista ou tradicional, conforme preconizado pela teoria de Finanças. Entretanto, se por um lado, essa análise é parte importante do processo de decisão e análise do risco de crédito de qualquer empresa, ao fornecer a probabilidade, calcada em dados históricos, do risco de inadimplência da operação de crédito, por outro, considerando a falta de confiabilidade e exatidão dos documentos que são exigidos, como é, por exemplo, o balanço patrimonial, deveriam ser considerados outros fatores na análise e decisão de concessão de crédito, tais como: 1) nível de escolaridade do proprietário; 2) tempo de funcionamento da empresa; 3) experiência anterior do proprietário no setor; 4) localização da empresa; 5) nível de tecnologia nos seus processos; e 6) finalidade do crédito.

Para Gonçalves, Pessoa e Moreira (2007) são vários os fatores que contribuem para aumentar a distância da realidade das MPE's e as empresas de maior porte, que em conjunto ou em separado explicam a sua elevada taxa de mortalidade em anos iniciais. Segundo esses autores, os fatores externos seriam: 1) legislação específica e tributação; 2) condições econômicas e de exportação; e 3) o mercado (ambiente concorrencial). Enquanto os fatores internos seriam: 1) organizacionais (planejamento e acesso / adaptação ao mercado); 2.) humanos (capacitação gerencial); 3) tecnológicos (acesso a tecnologia); e 4) financeiros (capital e acesso ao capital).

Diante da relevância do financiamento para suas atividades, o apoio gerencial e financeiro passa a ser fundamental para a sobrevivência das MPE's, no sentido de instrumentalizá-las e prepará-las para as dificuldades e exigências do mercado, pois a realidade desse segmento mostra que elas apresentam uma demanda por instrumentos creditícios com menos burocracia que, sem descuidar o risco de default, viabilizem o acesso aos recursos, possibilitando, assim, seu crescimento e desenvolvimento.

No que se refere à literatura nacional sobre o tema da análise e concessão de crédito, destacam-se as obras de Schrickel (1997), Blatt (1998), Berni (1999) e Pandeló (2000), que realizaram estudos de caso de concessões específicas, bem como análises executadas por especialistas de crédito. Merece destaque também o aumento, nos últimos anos, de pesquisas cujo foco foi analisar a aplicação e a eficiência do uso de técnicas estatísticas na gestão crédito, tais como Faria (2006), Bertucci, Guimarães e Bressan (2003), Cia (2003), Marques e Kloeckner (2002), Horta e Carvalho (2002) e Minussi et al. (2001). 


\section{Dados Empíricos da Sobrevivência das MPE's}

Um levantamento do Sebrae (2004), realizado com empresários (resposta a questionários) identificou que os dois fatores financeiros que mais contribuem para a falência das MPE's eram: 1) capital, tanto inicial quanto de giro para $42 \%$ dos participantes da pesquisa; e 2) problemas financeiros, identificados em $21 \%$ das respostas. Essa pesquisa apontou também que os recursos investidos (capital médio investido em ativos fixos) e em capital de giro nas MPE's falidas correspondia à metade e a um terço, respectivamente, do valor investido nas empresas ainda em atividade.

Na perspectiva de Solomon (1986), a escassez crônica de recursos cria obstáculos para o pequeno empresário desde o início, impedindo que ele faça os investimentos necessários em maquinário e tecnologia para a substituição de mão-de-obra, de maneira a elevar sua produtividade e lucratividade. Essa dificuldade resulta em empresas com custos e despesas elevados, que operam com baixas margens de ganho e, consequentemente, ineficientes em termos operacionais. Solomon (1986, p. 271) acrescenta ainda que a "escassez de capital é a principal responsável pelo fato de que as pequenas empresas estão comumente fadadas a períodos de vida muito curtos”.

Segundo Gonçalves et al. (2007), o acesso a crédito é elemento fundamental para definir o sucesso das MPE's, pois se liga diretamente ao aumento e manutenção de sua capacidade produtiva. Ainda segundo esses autores, como ciclo vicioso, as dificuldades para obter crédito aumentan as dificuldades produtivas, contribuindo, desse modo, para a sua mortalidade.

Entretanto, apesar das diversas dificuldades enfrentadas pelas MPE's, em estudo mais recente o Sebrae (2007) demonstrou que o número de MPE's que estão conseguindo sobreviver no mercado tem aumentado, se comparado ao estudo anterior apresentado em 2004. O índice passou de 50,6\% em 2004, para 78\% em 2007. Outros aspectos relevantes, apontados por esse relatório, dizem respeito aos fatores como condicionantes para sobrevivência das MPE's considerados pelos empresários de empresas ativas entrevistados: "carga tributária elevada" e a "falta de crédito bancário", apontados como os mais relevantes por $65 \%$ e $22 \%$, respectivamente. Já para os empresários de empresas extintas, entre os fatores de maior relevância também aparecem: a "falta de capital de giro" e "carga tributária, encargos e impostos” como sendo os mais relevantes para $22 \%$ e $13 \%$, respectivamente.

\section{Metodologia de Pesquisa}

Esta pesquisa é do tipo descritivo que, segundo Gil (2002), tem como objetivo primordial descrever as características de determinada população ou fenômeno, ou então o estabelecimento de relações entre as variáveis que, no seu contexto específico, foi o de estabelecer relação entre características socioeconômicas e financeiras de empresas e empreendedores e a sua possibilidade de inadimplência.

Foram utilizados dados secundários, de micro e pequenas empresas do Estado de Minas Gerais, conforme classificação do programa apresentada na Tabela 1, coletados nos relatórios do sistema gerencial do BDMG, no âmbito do programa GERAMINAS, que tiveram seus pedidos de crédito aprovados e que receberam recursos.

Tabela 1

Critério de Classificação das Empresas Estudadas

\begin{tabular}{ll}
\hline Tipo Empresa & Faturamento Anual* \\
\hline Micro Empresa $[\mathrm{ME}]$ & até $\mathrm{R} \$ 288.515,00$ \\
Empresa de Pequeno Porte $[\mathrm{EPP}]$ & entre R\$ 288.516,00 e R\$ 2.308.958,00 \\
\hline
\end{tabular}

Nota. Fonte: elaboração própria.

(*) categorias definidas pelo Programa GERAMINAS. 
A pesquisa é do tipo cross-section, na qual o corte temporal utilizou dados dos financiamentos concedidos no âmbito do programa, coletados no período compreendido entre junho de 1997, ano em que teve início a implantação do programa, e janeiro de 2006. O universo da pesquisa constituiu-se, portanto, de micros e pequenas empresas do Estado de Minas Gerais, atendidas pelo programa do BDMG. Na análise dos fatores condicionantes da inadimplência no âmbito do programa foi utilizada a técnica Regressão Logística Binária.

As variáveis independentes utilizadas na pesquisa, em sua maioria citadas na literatura pesquisada, se referem a características tanto dos empreendedores, quanto das micro e pequenas empresas do programa GERAMINAS. A Tabela 2 apresenta a descrição das variáveis independentes inicialmente selecionadas para a pesquisa.

Tabela 2

Resumo das Variáveis Independentes

\begin{tabular}{|c|c|c|c|}
\hline VARIÁVEL & SIGLA & CÁLCULO / FONTE & $\begin{array}{c}\text { INTERPRETAÇÃO / EXPLICAÇÃO } \\
\text { TEÓRICA }\end{array}$ \\
\hline $\begin{array}{l}\text { Proporção do } \\
\text { faturamento no } \\
\text { valor do } \\
\text { financiamento }\end{array}$ & FATFIN & $\begin{array}{l}\text { valor do faturamento (R\$) } \\
\text { do ano imediatamente } \\
\text { anterior à concessão do } \\
\text { financiamento sobre o } \\
\text { valor do financiamento } \\
\text { concedido }\end{array}$ & $\begin{array}{l}\text { representa a relação entre o valor do } \\
\text { faturamento anual em reais relativamente ao } \\
\text { valor em reais do financiamento concedido }\end{array}$ \\
\hline $\begin{array}{l}\text { Proporção de } \\
\text { capital de giro } \\
\text { no valor do } \\
\text { projeto }\end{array}$ & CGPJ & $\begin{array}{c}\text { valor para capital de giro } \\
\text { sobre o valor total do } \\
\text { projeto }\end{array}$ & $\begin{array}{c}\text { é a proporção do valor informado no projeto } \\
\text { para capital de giro, no valor total informado } \\
\text { para o referido projeto }\end{array}$ \\
\hline $\begin{array}{l}\text { Faturamento } \\
\text { anual }\end{array}$ & FATANEM & $\begin{array}{l}\text { valor da receita bruta anual } \\
\text { da empresa, declarada pelo } \\
\text { contador do solicitante do } \\
\text { financiamento }\end{array}$ & $\begin{array}{l}\text { faturamento anual da empresa demandante, em } \\
\text { Reais }\end{array}$ \\
\hline $\begin{array}{l}\text { Valor dos Bens } \\
\text { do Avalista em } \\
\text { relação ao } \\
\text { financiamento }\end{array}$ & $\begin{array}{l}\text { BENAVAL } \\
\text { FIN }\end{array}$ & $\begin{array}{l}\text { valor dos bens do avalista } \\
\text { sobre o valor do } \\
\text { financiamento }\end{array}$ & $\begin{array}{c}\text { representa o valor em Reais, dos bens do } \\
\text { avalista, na sua declaração de IR do exercício } \\
\text { imediatamente anterior ao ano da concessão } \\
\text { do financiamento, em relação ao valor do } \\
\text { financiamento }\end{array}$ \\
\hline $\begin{array}{l}\text { Localização da } \\
\text { Empresa }\end{array}$ & LOCEX & $\begin{array}{l}\text { variável informada no } \\
\text { formulário de solicitação } \\
\text { do financiamento }\end{array}$ & $\begin{array}{c}\text { Indica se o solicitante está localizado na } \\
\text { Região Metropolitana de Belo Horizonte ou na } \\
\text { demais Mesorregiões do Estado }\end{array}$ \\
\hline $\begin{array}{l}\text { Setor de } \\
\text { Atividade }\end{array}$ & SEATEX & $\begin{array}{l}X=0 \text { (comércio) } \\
X=1 \text { (serviços) } \\
X=2 \text { (indústria) }\end{array}$ & representa o setor de atuação da empresa \\
\hline $\begin{array}{l}\text { Tempo de } \\
\text { Atividade da } \\
\text { Empresa }\end{array}$ & TAE & $\begin{array}{l}\text { variável informada no } \\
\text { formulário de solicitação } \\
\text { do financiamento }\end{array}$ & $\begin{array}{l}\text { representa o tempo de atividade da empresa, } \\
\text { calculado em anos, de acordo com a data de } \\
\text { fundação constante no contrato de constituição } \\
\text { da mesma }\end{array}$ \\
\hline $\begin{array}{c}\text { Nível de } \\
\text { Informatização }\end{array}$ & NIEX & $\begin{array}{l}\text { variável informada no } \\
\text { formulário de solicitação } \\
\text { do financiamento }\end{array}$ & $\begin{array}{c}\text { essa informação se relaciona com o nível de } \\
\text { organização da empresa, medida pela qualidade } \\
\text { do seu sistema de informação gerencial, podendo } \\
\text { ser: baixo, intermediário ou avançado }\end{array}$ \\
\hline
\end{tabular}

Continua 


\section{Tabela 2 (continuação)}

\begin{tabular}{|c|c|c|c|}
\hline VARIÁVEL & SIGLA & CÁLCULO / FONTE & $\begin{array}{c}\text { INTERPRETAÇÃO / EXPLICAÇÃO } \\
\text { TEÓRICA }\end{array}$ \\
\hline $\begin{array}{l}\text { Percepção de } \\
\text { Mercado }\end{array}$ & PERCPME & $\begin{array}{l}\text { variável informada no } \\
\text { formulário de solicitação } \\
\text { do financiamento }\end{array}$ & $\begin{array}{c}\text { representa a percepção do empreendedor sobre } \\
\text { o seu mercado no momento do pedido do } \\
\text { financiamento. As percepções de mercado são } \\
\text { representadas por: decrescente, estável e } \\
\text { crescente }\end{array}$ \\
\hline \multirow{3}{*}{$\begin{array}{c}\text { Nível de } \\
\text { Escolaridade }\end{array}$} & NESC1 & $\begin{array}{l}\text { variável informada no } \\
\text { formulário de solicitação } \\
\text { do financiamento }\end{array}$ & \multirow{2}{*}{$\begin{array}{c}\text { representa o nível de escolaridade menor ou } \\
\text { igual ao primeiro grau (menor ou igual ao } 1^{\circ} \text { ) } \\
\text { representa o segundo grau de escolaridade. } \\
\text { Tem um nível de escolaridade superior ao } \\
\text { primeiro grau, podendo ter o segundo grau } \\
\text { completo ou incompleto (maior que } 1^{\circ} \text { grau, } \\
\text { menor ou igual ao } 2^{\circ} \text { ) }\end{array}$} \\
\hline & NESC2 & $\begin{array}{l}\text { variável informada no } \\
\text { formulário de solicitação } \\
\text { do financiamento }\end{array}$ & \\
\hline & NESC3 & $\begin{array}{l}\text { variável informada no } \\
\text { formulário de solicitação } \\
\text { do financiamento }\end{array}$ & $\begin{array}{c}\text { representa a escolaridade de nível superior. } \\
\text { Tem um nível de escolaridade superior ao } \\
\text { segundo grau, podendo ter o curso superior } \\
\text { completo ou incompleto (maior que } 2^{\circ} \text { grau, } \\
\text { menor ou igual a superior) }\end{array}$ \\
\hline $\begin{array}{l}\text { Experiência na } \\
\text { Empresa }\end{array}$ & EXPE1 & $\begin{array}{c}\text { variável Dummy que } \\
\text { sinaliza: experiência } \\
\text { menor do que um ano } \\
\text { variável Dummy que } \\
\text { sinaliza: experiência maior } \\
\text { do que um ano e menor do } \\
\text { que cinco anos } \\
\text { variável Dummy que } \\
\text { sinaliza: experiência maior } \\
\text { do que cinco anos }\end{array}$ & $\begin{array}{l}\text { representa o tempo de experiência do sócio } \\
\text { majoritário na empresa (em anos) }\end{array}$ \\
\hline
\end{tabular}

Nota. Fonte: adaptado de Guimarães, J. B. (2002). Financiamento de micros e pequenas empresas em uma instituição pública de crédito (pp. 71-74). Dissertação de mestrado, Pontifícia Universidade Católica de Minas Gerais, Belo Horizonte, MG, Brasil.

Como o foco desta pesquisa está em identificar e analisar os fatores condicionantes da inadimplência no âmbito do Programa GERAMINAS, para a variável dependente, foi considerada inadimplente a empresa que estivesse com mais de 90 dias de atraso, além do período de carência, que é de seis meses. Os valores financiados pelo programa variam entre o mínimo de R\$ 5 mil e o máximo de R\$ 360 mil; valores inferiores a R\$ 25 mil são considerados como financiamento de capital de giro que, ao contrário do financiamento para investimento em ativos fixos, não demandam comprovação dos investimentos realizados. Os recursos do programa podem financiar até 80\% dos investimentos, desde que observados determinados limites.

As unidades de análise desta pesquisa foram micro e pequenas empresas do Estado de Minas Gerais que obtiveram financiamento junto ao BDMG entre 1997 e 2006. As unidades de observação foram informações socioeconômicas dos empresários e avalistas, bem como dados econômico-financeiros das MPE’s, constantes nos relatórios do sistema gerencial do programa.

O modelo utilizado na pesquisa foi a Regressão Logística Binária; este modelo é descrito na próxima seção. Foram analisados os dados de todas as empresas (universo) constantes da base de dados encaminhada pela instituição, composta por 17.743 empresas, pertencentes a 29.192 sócios, em um total de 25.616 processos de financiamento; algumas empresas obtiveram recursos mais de uma vez no período analisado. Desses processos, 834 estavam inadimplentes (3,3\%) e 24.782 (96,7\%) estavam adimplentes, na realização da pesquisa. 


\section{Método}

Para a análise dos fatores associados à inadimplência no âmbito do programa estudado foi utilizado o modelo de Regressão Logística Binária, cujo uso mais comum se dá quando a variável dependente é dicotômica e as variáveis independentes são de qualquer tipo. O presente estudo tem como variável dependente a inadimplência junto ao programa (sim e não); e variáveis independentes são classificadas em três grupos: 1) socioeconômicas (sócios e avalista); 2) econômico-financeiras (empresas) e, 3) financiamento, conforme Figura 1.

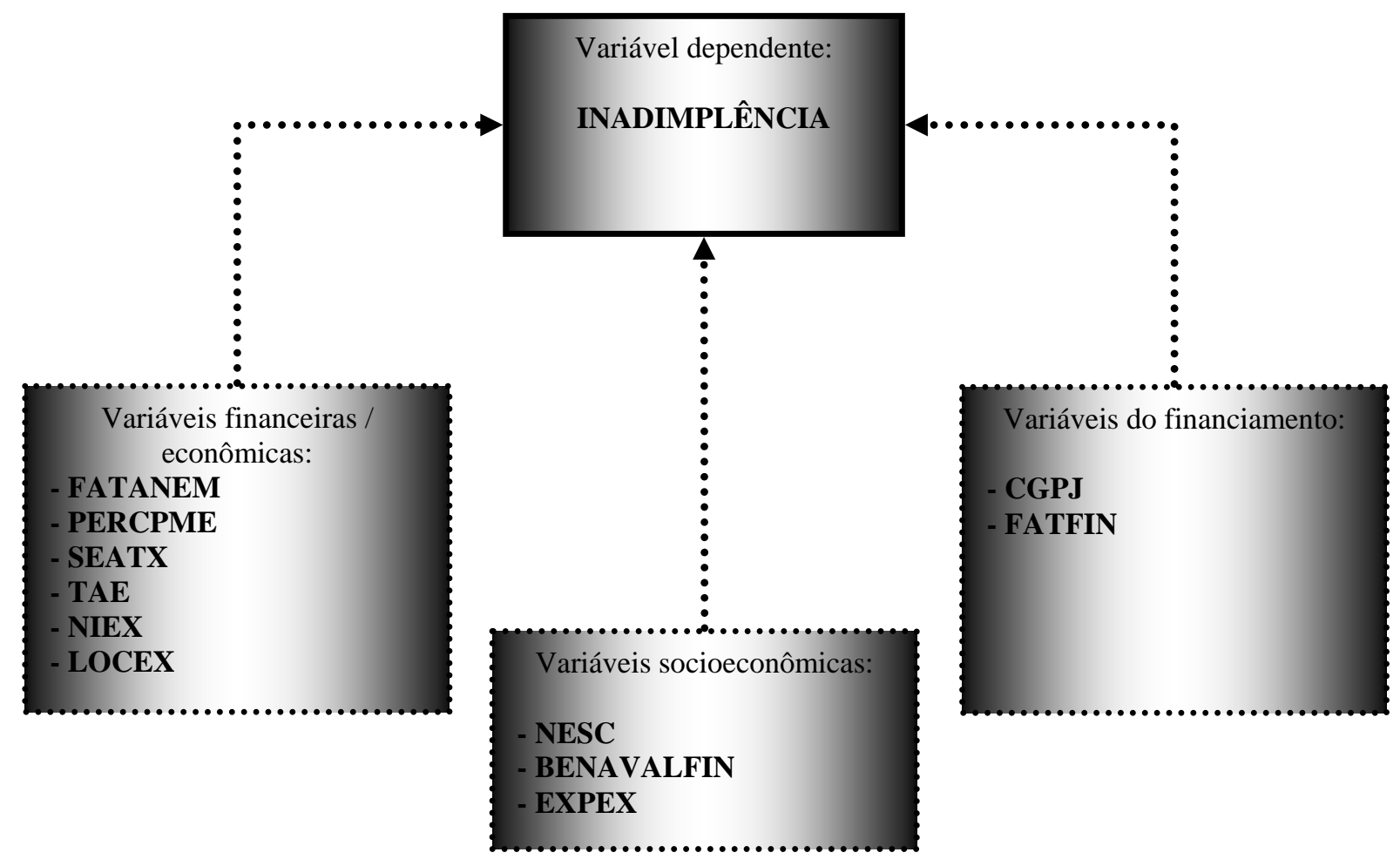

Figura 1. Conjunto das Variáveis Estudadas

Fonte: elaborada pelos autores.

A Regressão Logística Binária é um modelo de regressão em que a variável dependente é dicotômica. Assim, Y assume apenas dois valores, 1 para representar a resposta considerada sucesso e 0 para a considerada insucesso. No presente trabalho, a variável dependente assumiu o valor 1 , se a empresa estivesse inadimplente (mais de 90 dias de atraso no pagamento das parcelas do financiamento); e 0 , se ela estivesse adimplente. Uma das vantagens da regressão logística é que se necessita apenas saber se um evento ocorreu para usar um valor dicotômico como variável dependente, valor a partir do qual a equação prediz, informando a probabilidade de o evento ocorrer ou não. Se o valor da probabilidade for superior a 0,50, o caso será classificado como sucesso (grupo dos inadimplentes); em caso contrário, como insucesso (grupo dos adimplentes).

Deve ser ressaltado, entretanto, que quando a transformação logística é utilizada, a interpretação dos coeficientes da regressão é diferente daquela utilizada quando a variável dependente é métrica. $\mathrm{O}$ modelo de regressão logística integra a classe dos modelos lineares generalizados, ou seja, aqueles que se tornam lineares por meio da aplicação de algum tipo de transformação.

Considere o modelo abaixo, o qual utiliza apenas uma variável independente $\mathrm{X}_{1}$ :

$$
Y=e^{\beta_{0}+\beta_{1} x_{1}}
$$


Ao se obter o logaritmo neperiano da expressão anterior, tem-se o seguinte modelo linear:

$$
\operatorname{Ln}(Y)=\beta_{0}+\beta_{1} x_{1}
$$

Para o modelo de regressão logística, Y é dado por:

$$
Y=\frac{p}{1-p}
$$

Dessa forma, tem-se o modelo do tipo:

$$
\operatorname{Ln}\left(\frac{p}{1-p}\right)=\beta_{0}+\beta_{1} x_{1}
$$

Generalizando para um número qualquer de variáveis, o modelo de regressão logística pode ser escrito da seguinte forma:

$$
\operatorname{Ln}\left(\frac{p}{1-p}\right)=\beta_{0}+\sum \beta_{x}
$$

sendo:

. $\quad p$ = a probabilidade de ocorrência de inadimplência;

- $\beta_{0}=$ constante do modelo;

- $\beta_{x}=$ efeitos (parâmetros) associados com as variáveis explicativas;

- $x$ = as covariáveis para cada processo de financiamento.

O parâmetro do modelo indica a mudança que ocorre no logito, dada uma mudança unitária na variável independente. A exponencial do parâmetro fornece as razões de chance (odds ratio), que medem a força da associação entre determinado fator e a variável dependente. A razão de chance menor que um significa que a variável atua reduzindo o risco de inadimplência. Por sua vez, quando a razão de chance é maior do que um, a variável está atuando como fator de risco para a inadimplência.

A análise dos dados foi realizada, utilizando o pacote estatístico Statistical Package for the Social Sciences [SPSS], versão 13.0. Os resultados do modelo foram apresentados como razões de chance (odds ratio). Foram considerados os resultados em nível de significância de $5 \%$ ( $p$-value $<0,05$ ). As variáveis independentes foram categorizadas da seguinte forma:

\section{1) Variáveis Econômico-Financeiras das Empresas}

\section{. Faturamento Anual da Empresa [FATANEM]}

FATANEM1: 1 se o faturamento anual for menor ou igual a $\mathbf{R} \mathbf{\$ 2 8 8 . 5 1 5 , 0 0 ,} 0$ caso contrário (categoria de referência).

FATANEM2: 1 se o faturamento anual for maior do que $\mathbf{R} \$ \mathbf{2 8 8 . 5 1 6 , 0 0}$ e menor ou igual a $\mathbf{R} \$$ 2.308.958,00, 0 caso contrário.

\section{. Percepção de Mercado [PERCPME]}

PERCPME1: 1 se o mercado for decrescente, 0 caso contrário (categoria de referência).

PERCPME2: 1 se o mercado for estável, 0 caso contrário. 
PERCPME3: 1 se o mercado for crescente, 0 caso contrário.

\section{Setor de Atividade da Empresa [SEATEX]}

SEATE1: 1 se a empresa for comercial, 0 caso contrário (categoria de referência).

SEATE2: 1 se a empresa for prestadora de serviços, 0 caso contrário.

SEATE3: 1 se a empresa for industrial, 0 caso contrário.

\section{. Tempo de Atividade da Empresa [TAE]}

TAE1: 1 se a empresa tiver menos de um ano de existência, 0 caso contrário (categoria de referência).

TAE2: 1 se a empresa tiver mais de um e menos do que 5 anos de existência, 0 caso contrário.

TAE3: 1 se a empresa tiver mais do que 5 anos de existência, 0 caso contrário.

\section{. Nível de Informatização da Empresa [NIEX]}

NIE1: 1 se o nível de informatização declarado pelo sócio for antigo, 0 caso contrário (categoria de referência).

NIE2: 1 se o nível de informatização declarado pelo sócio for intermediário, 0 caso contrário.

NIE3: 1 se o nível de informatização declarado pelo sócio for moderno, 0 caso contrário.

\section{. Localização da Empresa [LOCEX]}

LOCE1: 1 se a empresa estiver localizada na Região Metropolitana de Belo Horizonte, 0 caso contrário (categoria de referência).

LOCE2: 1 se a empresa estiver localizada fora da Região Metropolitana de Belo Horizonte, 0 caso contrário.

\section{2) Variáveis Socioeconômicas (sócios / avalistas)}

\section{. Nível de Escolaridade do Sócio [NESCX]}

NESC1: 1 se o nível de escolaridade do sócio for menor ou igual ao primeiro grau, 0 caso contrário (categoria de referência).

NESC2: 1 se o nível de escolaridade do sócio for maior do que o primeiro e menor do que o segundo grau, 0 caso contrário.

NESC3: 1 se o sócio tiver formação superior (completo ou incompleto), 0 caso contrário.

\section{. Valor dos Bens do Avalista em Relação ao Financiamento [BENAVALFIN]}

BENAVALFIN1: 1 se valor declarado dos bens do sócio for até três vezes maior do que o valor financiado, 0 caso contrário (categoria de referência).

BENAVALFIN2: 1 se valor declarado dos bens do sócio for de três até oito vezes maior do que o valor financiado, 0 caso contrário.

BENAVALFIN3: 1 se valor declarado dos bens do sócio for superior a oito vezes o valor financiado, 0 caso contrário.

\section{. Tempo de Experiência na Empresa [EXPEX]:}


EXPE1: 1 se o tempo de experiência do sócio majoritário na empresa for menor do que um ano, 0 caso contrário (categoria de referência).

EXPE2: 1 se o tempo de experiência do sócio majoritário na empresa for maior do que um e menor do que cinco anos, 0 caso contrário.

EXPE3: se o tempo de experiência do sócio majoritário na empresa for maior do que cinco anos, 0 caso contrário.

\section{3) Variáveis do Financiamento}

\section{. Proporção de Capital de Giro do Projeto [CGPJ]}

CGPJ1: 1 se a proporção de capital de giro for menor ou igual a $\mathbf{2 0 \%}$ do projeto, 0 caso contrário (categoria de referência).

CGPJ2: 1 se a proporção de investimentos fixos do projeto for $\mathbf{2 0}$ a $\mathbf{5 0 \%}$ do projeto, 0 caso contrário.

CGPJ3: 1 se a proporção de investimentos fixos do projeto for acima de $\mathbf{5 0 \%}$ do projeto, 0 caso contrário.

\section{. Faturamento Anual da Empresa sobre o Valor Financiado [FATFIN]}

FATFIN1: 1 se o faturamento anual for até 6 vezes maior do que o valor financiado, 0 caso contrário (categoria de referência).

FATFIN2: 1 se o faturamento anual for de 6 até 12 vezes maior do que o valor financiado, 0 caso contrário.

FATFIN3: 1 se o faturamento anual representar mais do que 12 vezes o valor financiado, 0 caso contrário.

Assim, equação final do modelo pode ser escrita da seguinte forma:

$$
\begin{aligned}
\ln \left(\frac{p}{1-p}\right)= & \beta_{0}+\text { FATANEM } \beta_{1}+\text { PERCPME } \beta_{2}+\text { SEATE } \beta_{3}+\text { TAE } \beta_{4}+\text { NIE } \beta_{5}+\text { LOCE } \beta_{6}+ \\
& +N E S C X \beta_{7}+\text { BENAVALFIN } \beta_{8}+\text { EXPE } \beta_{9}+\text { CGPJ } \beta_{10}+\text { FATFIN } \beta_{11}
\end{aligned}
$$

\section{ANÁLISE E DISCUSSÃO DOS DADOS}

Nesta seção são apresentados os resultados obtidos com aplicação do modelo de Regressão Logística Binária. A interpretação substantiva, neste estudo, está baseada em razões de chances (odds ratio) apresentadas na Tabela 3, seguida da interpretação para cada variável incluída no modelo. 
Tabela 3:

\section{Parâmetros Estimados e Razões de Chances (Odds Ratio) do Modelo Logístico Binário para} Inadimplência em Processos de Concessão de Crédito

\begin{tabular}{|c|c|c|c|}
\hline & Parâmetros & p-value & Razões de chance \\
\hline Constante & $-2,262$ & & \\
\hline \multicolumn{4}{|c|}{ - Faturamento Anual da Empresa (FATANEM) } \\
\hline < a R\$288.515,00 (ME) & 0,000 & & 1,000 \\
\hline $\mathrm{R} \$ 288.516,00$ a $\mathrm{R} \$ 2.308 .958,00$ (EPP) & $0,254 * * *$ & 0,009 & 1,289 \\
\hline \multicolumn{4}{|l|}{ - Percepção de Mercado (PERCPME) } \\
\hline Decrescente & 0,000 & & 1,000 \\
\hline Estável & $-0,983^{* *}$ & 0,016 & 0,374 \\
\hline Crescente & $-0,822^{* *}$ & 0,038 & 0,440 \\
\hline \multicolumn{4}{|c|}{ - Setor de Atividade da Empresa (SEATEX) } \\
\hline Comercial & 0,000 & & 1,000 \\
\hline Prestadora de serviços & 0,186 & 0,135 & 1,205 \\
\hline Industrial & $0,253^{* *}$ & 0,014 & 1,288 \\
\hline \multicolumn{4}{|l|}{ - Tempo de Atividade da Empresa (TAE) } \\
\hline$<1$ ano & 0,000 & & 1,000 \\
\hline 1 a 5 anos & $-0,444^{* * *}$ & 0,001 & 0,641 \\
\hline$>5$ anos & $-0,703^{* * *}$ & 0,000 & 0,495 \\
\hline \multicolumn{4}{|c|}{ - Nível de Informatização da Empresa (NIEX) } \\
\hline Antigo & 0,000 & & 1,000 \\
\hline Intermediário & $0,312^{* *}$ & 0,015 & 1,366 \\
\hline Moderno & 0,168 & 0,233 & 1,183 \\
\hline \multicolumn{4}{|l|}{ - Localização da Empresa (LOCEX) } \\
\hline Região Metropolitana de BH & 0,000 & & 1,000 \\
\hline Região Não Metropolitana & 0,015 & 0,872 & 1,015 \\
\hline \multicolumn{4}{|l|}{ - Nível de Escolaridade do Sócio (NESCX): } \\
\hline Primeiro grau & 0,000 & & 1,000 \\
\hline Segundo grau & $0,263^{* *}$ & 0,016 & 1,301 \\
\hline Superior & 0,184 & 0,148 & 1,202 \\
\hline \multicolumn{4}{|c|}{ - Valor dos Bens do Avalista (BENAVALFIN) } \\
\hline Até 3 vezes maior & 0,000 & & 1,000 \\
\hline 3 a 8 vezes maior & $-0,196 * *$ & 0,030 & 0,822 \\
\hline Superior a 8 vezes & $-0,618^{* * *}$ & 0,000 & 0,539 \\
\hline \multicolumn{4}{|c|}{ - Tempo de Experiência na Empresa (EXPEX) } \\
\hline$<1$ ano & 0,000 & & 1,000 \\
\hline 1 a 5 anos & $-0,180$ & 0,220 & 0,835 \\
\hline$>5$ anos & $-0,486 * * *$ & 0,003 & 0,615 \\
\hline
\end{tabular}

Continua 


\section{Tabela 3 (continuação)}

Parâmetros p-value Razões de chance

\begin{tabular}{lccc}
\hline - Proporção de Capital de Giro do Projeto (CGPJ) & & & \\
< 20\% do projeto & 0,000 & 1,000 \\
20 a 50\% do projeto & $0,534^{* *}$ & 0,022 & 1,707 \\
$>$ 50\% do projeto & $0,456^{*}$ & 0,054 & 1,578 \\
- Faturamento Anual da Empresa / Financiamento (FATFIN) & & & 1,000 \\
Até 6 vezes maior & 0,000 & & 0,854 \\
6 a 12 vezes maior & $-0,158^{*}$ & 0,064 & 0,693 \\
Superior a 12 vezes & $-0,366^{* * *}$ & 0,000 & \multicolumn{2}{c}{} \\
\hline
\end{tabular}

Nota. Fonte: elaborada pelos autores (dados da pesquisa).

***, ** e * correspondem à significância estatística nos níveis de $1 \%, 5 \%$ e $10 \%$, respectivamente.

A seguir é feita a análise das razões de chance (odds ratio) de cada variável.

\section{Faturamento}

Para a variável faturamento que, no caso desta pesquisa, define a natureza da empresa (ME ou EPP), o resultado encontrado contraria o que argumentam Nucci (1999), Evans (1987) e Oliveira, Najberg e Puga (2000), de que existe relação direta entre porte e sobrevivência, ou seja, quanto maior o porte da empresa, maiores seriam as chances de sobrevivência e, portanto, de pagamento de suas obrigações de crédito. Os resultados do modelo mostram que empresas de pequeno porte (faturamento anual entre $\mathrm{R} \$ 288.516,00$ e $\mathrm{R} \$ 2.308 .958,00$ ) apresentam chances $28,9 \%$ maiores de ser inadimplentes, se comparadas com as microempresas, de faturamento menor que R\$ 288.515,00.

\section{Percepção de Mercado}

Conforme se observa nos sinais dos parâmetros do modelo para a percepção do mercado, há uma variação inversa entre esta e a inadimplência, ou seja, quanto mais estável ou crescente for o mercado, menores são as chances de inadimplência do demandante do crédito. Para a percepção de mercado, a análise revelou que uma empresa que atua em um mercado crescente tem uma chance 56,0\% menor de ser inadimplente, quando comparadas com aquelas que veem o mercado como decrescente. Para aquelas que atuam em um mercado estável, as chances de ser inadimplente diminuem em $62,6 \%$, se comparadas às de perspectiva decrescentes. Esses resultados sugerem que empresas que têm estabilidade ou a possibilidade de crescimento das suas atividades são mais aptas em honrar os compromissos creditícios assumidos. O fato é perfeitamente explicável: quanto maiores as oportunidades a serem exploradas por uma empresa, maiores são as possibilidades de ela aumentar sua lucratividade e, consequentemente, de manter-se adimplente.

\section{Setor de Atividade da Empresa}

Quando analisado o setor de atividade da empresa, observa-se que aquelas do setor industrial apresentam uma chance $28,8 \%$ superior de serem inadimplentes, se comparadas às do setor comercial. Os resultados para as prestadoras de serviços não se mostraram significantes estatisticamente. O resultado acima não foi verificado na literatura consultada. Possíveis causas que explicam essa propensão maior para a inadimplência do setor industrial seriam: 1) a maior complexidade (na produção e gestão); 2) custos e despesas mais elevados; 3) limitação do escopo corporativo, pois 
geralmente são mais concentradas no seu core-business, tendo, por isso, foco em poucos produtos, tornando-as mais suscetíveis a sazonalidades.

\section{Tempo de Atividade da Empresa}

No que se refere ao tempo de atividade da empresa, pode-se observar pelos sinais dos parâmetros do modelo que, quanto maior o tempo em que a empresa está no mercado, menores são as chances de inadimplência. Ao comparar com empresas com menos de 1 ano no mercado, nota-se que aquelas que estão no mercado de 1 a 5 anos possuem uma chance 35,9\% inferior de estarem inadimplentes e aquelas com tempo superior a 5 anos têm as chances reduzidas em 50,5\%. Esse resultado corrobora a argumentação de Audretsch (1999), de que nos primeiros anos de vida de uma organização, são muitas as incertezas quanto às vendas, competência dos gestores e funcionários, adequação produtiva, fatores que, com o passar do tempo, têm sua influência negativa minimizada, fato que justificaria a sua melhora de desempenho e, conseqüentemente, sua capacidade de honrar os compromissos financeiros assumidos.

\section{Nível de Informatização da Empresa}

Quanto ao nível de informatização, os resultados não se mostraram significantes estatisticamente para empresas tidas como modernas. Surpreendentemente, aquelas de nível intermediário apresentam 36,6\% a mais de chances de serem inadimplentes, se comparadas ao grupo de referência (informatização antiga). Esses resultados contrariam os encontrados por Guimarães (2002), que realizou estudo semelhante com uma amostra do universo utilizado nesta pesquisa. Tal constatação pode sinalizar que os sócios das empresas pesquisadas não utilizam ou não sabem aproveitar o potencial que a informática pode trazer para a gestão da empresa. É situação comum, principalmente quando se consideram as empresas do interior do Estado. Infelizmente ainda se observa um considerável nível de aversão à informática por parte dos empresários, geralmente maior em pessoas com idade maior.

\section{Localização da Empresa}

No que se refere à associação da localização da empresa na região metropolitana de Belo Horizonte ou não, com a inadimplência, os dados não confirmaram essa relação (sem significância estatística). Em outras palavras, a localização da empresa não a condiciona a ser adimplente ou inadimplente.

\section{Nível de Escolaridade do Sócio}

No que se refere ao nível de escolaridade do sócio, observa-se que aqueles com segundo grau apresentam maior probabilidade $(30,1 \%)$ de ser inadimplente, quando comparado aos que possuem apenas o primeiro grau. Já para aqueles com escolaridade de nível superior os resultados não foram significantes estatisticamente, mas com indícios de que é maior do que aqueles com primeiro grau, mas menor do que aqueles com escolaridade de nível médio. São constatações que contrariam a idéia de que quanto maior a escolaridade, maior a percepção e a capacidade do empresário gerenciar melhor o seu negócio. Uma possível explicação para isso seria que o empresário que tem apenas o primeiro grau tem menores oportunidades de inserção no mercado ou limitações para sucesso profissional, fato que possivelmente faça com que ele tenha propensão maior para honrar os seus compromissos.

\section{Valor dos Bens do Avalista em Relação ao Financiamento (BENAVALFIN)}

O valor dos bens do avalista se mostrou fator protetor contra a inadimplência. Neste caso, quanto maior o valor dos bens do avalista, menores são as chances de ocorrer inadimplência. Tendo um avalista com bens de 3 a 8 vezes maiores que o valor do financiamento, a empresa possui uma chance 
17,8\% menor de ser inadimplente, se comparados com aqueles com bens até 3 vezes superior ao financiamento. Já aqueles com bens acima de 8 vezes do valor do financiamento as chances de serem inadimplentes, se comparados ao grupo de referência, são 46,1\% menores. Isso justifica a necessidade de exigir esta garantia por parte do Programa, principalmente por se tratar de recursos de origem pública.

\section{Tempo de Experiência na Empresa}

Conforme destaca Audretsch (1999) nos primeiros anos de vida de uma empresa, são muitas as incertezas quanto à demanda dos seus produtos, competência do empresário bem como dos empregados. Entretanto, com o passar do tempo, o empresário e seus funcionários adquirem experiência no ramo de atividade, fato que aumentaria as chances de sobrevivência da empresa no longo prazo.

Os resultados obtidos nesta pesquisa sinalizam que o tempo de experiência do sócio na empresa superior a 5 anos atua como fator influenciador da inadimplência. Pode-se observar que esses sócios têm as chances reduzidas em 38,5\% de serem inadimplentes, quando comparados àqueles com experiência recente na empresa (menor que 1 ano). Contudo os resultados não se mostraram significantes estatisticamente para aqueles com 1 a 5 anos de experiência no negócio. Apesar disso, pode-se dizer o seguinte: quanto maior a experiência do sócio no negócio, menores tendem a ser as dificuldades financeiras da empresa e, conseqüentemente, menor sua inadimplência. Tal constatação confirma o senso comum, assim como a maioria das pesquisas sobre micro e pequenas, cujos resultados indicam que, quanto maior a experiência de sócios, maior a probabilidade de sobrevivência da empresa e, portanto, de cumprimento de suas obrigações creditícias (Guimarães, 2002).

\section{Proporção de Capital de Giro do Projeto}

Quanto ao capital de giro, os resultados sinalizam que proporções maiores de capital de giro em relação ao projeto elevam as chances de inadimplência; contudo não existe um padrão definido de aumento das chances de inadimplência, na medida em que se aumenta a proporção de capital de giro em relação ao valor do projeto. Uma empresa cuja proporção é superior a 50\% tem aumentadas suas chances de ser inadimplente em $57,8 \%$, se comparadas àquelas em que a proporção do valor do financiamento é menor do que 20\% (significância de 10\% - apenas indícios). Para aquelas cuja proporção está entre 20 e 50\% do projeto a chance de inadimplência é 70,7\% maior, se comparadas ao grupo de referência. Observa-se que empresas que destinam acima de $20 \%$ do financiamento para capital de giro aumentam bastante sua chance de inadimplência. Essas constatações contrariam os resultados encontrados pelo Sebrae (2000), de que um dos maiores problemas de insucesso das MPE's seria a falta de capital de giro para as suas atividades. Em outras palavras, a imobilização excessiva em investimento fixo ou a utilização da maior parte de recursos próprios no projeto geraria problemas futuros relacionados à falta de capital de giro para operacionalização da empresa depois de realizado o financiamento. Uma possível explicação para isso seria que os recursos obtidos podem estar sendo utilizados para pagar outras dívidas e não para investir em ativos fixos ou na modernização da empresa que, a médio prazo, poderiam vir a garantir seu crescimento.

\section{Faturamento Anual da Empresa sobre o Valor Financiado}

O faturamento anual da empresa se mostrou como fator protetor para que a inadimplência não ocorra, o que já era esperado. Nesse caso, uma empresa com faturamento 12 vezes superior ao valor do financiamento tem uma chance $30,7 \%$ menor de ser inadimplente, quando comparada àquelas com faturamento anual de apenas 6 vezes o valor financiado. Os resultados não se mostraram significantes estatisticamente para faturamento de 6 a 12 vezes o valor do financiamento com nível de significância de $5 \%$, fornecendo apenas indícios (nível de significância de 10\%) de que uma empresa com este faturamento tem as chances de inadimplência reduzidas em 14,6\%, se comparadas com aquelas tidas 
como referência. Esses resultados, ao contrário de Guimarães (2002), confirmam a expectativa até intuitiva de que, quanto maior o porte da empresa em relação ao financiamento recebido, maior sua probabilidade de cumprimento de obrigações com credores.

Se por um lado a confirmação de que quanto maior o faturamento, menor é a tendência à inadimplência nas empresas pesquisadas, por outro, entretanto, não se pode dizer que o maior porte (ME e EPP) leva aos mesmos resultados, porque, conforme visto nos resultados da primeira variável, as segundas apresentaram chances $28,9 \%$ maiores de ser inadimplentes, se comparadas àquelas com as primeiras. Uma possível explicação para isso seria que o maior faturamento permite às EPP's solicitar valores maiores de financiamento, aumentando, assim, a possibilidade da inadimplência. A Tabela 5 apresenta uma síntese dos resultados encontrados e discutidos acima.

Tabela 5

Relação entre as Variáveis do Modelo e a Probabilidade de Inadimplência

\begin{tabular}{cc}
\hline Variável & Probabilidade de inadimplência com o aumento da variável \\
\hline FATANEM & Aumenta* \\
PERCPME & Se crescente ou estável diminui \\
SEATEX & Ser do setor industrial aumenta \\
TAE & Diminui \\
NIEX & Ter nível de informatização antigo diminui* \\
LOCEX & Insignificante estatisticamente \\
NESC & Nível médio diminui \\
BENAVALFIN & Diminui \\
EXPE & Diminui \\
CGPJ & Aumenta* \\
FATFIN & Diminui \\
\hline
\end{tabular}

Nota. Fonte: elaborada pelos autores.

As variáveis sinalizadas acima $(*)$ contrariam os resultados de outros autores ou o senso comum. $\mathrm{O}$ fato suscita novas pesquisas sobre o tema.

\section{CONSIDERAÇÕES FINAIS E CONCLUSÃO}

Esta pesquisa abordou o tema da inadimplência na concessão de crédito por parte de uma instituição pública estadual, visando identificar indicadores da possibilidade de inadimplência nos processos de financiamentos concedidos no âmbito do Programa GERAMINAS. Para tanto foi utilizada uma base de dados constituída por 17.743 empresas, pertencentes a 29.192 sócios, em um total de 25.616 processos de financiamento. O período de análise foi de junho de 1997 a janeiro de 2006, durante o qual foram liberados mais de R 518 bilhões (média de R\$ 19.415,82 por processo), destinados a financiar projetos orçados em mais de R\$ 673 bilhões, com 76,9\% do valor dos projetos sendo financiados pelo Programa. Pelos valores liberados e pela quantidade de empresas atendidas ressaltase, de início, tanto o volume dos dados analisados (universo), quanto o papel desempenhado pelo Programa para o crescimento e desenvolvimento de empresas, mesorregiões e do Estado. Destaca-se também que a quantidade de processos analisados, representativos de todas as mesorregiões do Estado, é fator que contribui para a generalização dos resultados encontrados nesta pesquisa. 
A grande maioria das pesquisas da área de Finanças concentra-se na análise de temas ligados às grandes corporações. Paralelo a isso, observa-se que o foco das pesquisas de temas ligados a MPE's está nas características e fatores que influenciam positivamente ou aumentam as suas chances de sucesso ou de sobrevivência. Dessa forma, a relevância desta pesquisa reside no fato de ter abordado um segmento ainda carente de estudos empíricos, na perspectiva de identificar se as características e fatores do insucesso das MPE's também contribuem para a possibilidade de inadimplência. Conforme salienta Guimarães (2002), o crédito às MPE's com qualidade e com condições adequadas à realidade do segmento é um dos grandes desafios para impulsionar o seu desenvolvimento, cuja importância e influência no PIB do País são incontestáveis, quando se analisa a quantidade de empregos e de renda pelos quais é responsável. Nesse sentido, resultados empíricos que identifiquem os fatores ou características das MPE's que aumentam a sua possibilidade de inadimplência, revestem-se de importância ainda maior, principalmente se for considerado que parte significativa do crédito a esse segmento advém de instituições financeiras públicas. Assim, a principal contribuição desta pesquisa foi a identificação de fatores e forças de influência sobre a inadimplência na concessão do crédito para o segmento de MPE's, destacando-se também os fatores que não se mostraram significantes, para os quais fica a sugestão de aprofundamento em pesquisas futuras.

É válido destacar que o nível de inadimplência do Programa estudado é relativamente baixo 3,26\%, devido principalmente às exigências do processo de financiamento, com destaque para as certidões negativas, envolvimento do contador da empresa e de um avalista em todos os processos, além das penalidades e prazos para obtenção de novos financiamentos para empresas inadimplentes. Isso sem mencionar a seriedade e a padronização da concessão do crédito por parte da instituição pesquisa.

Para a identificação dos fatores condicionantes da inadimplência nos processos de financiamento do programa estudado, foi utilizado o modelo de Regressão Logística Binária, modelo este mais indicado pela literatura e pela quantidade de dados. Sua adequação pode ser identificada pela quantidade de variáveis que apresentaram significância estatística e com o sinal ou influência esperada sobre a variável dependente (maioria). Ademais, ressalte-se que o desenvolvimento de metodologias baseadas em estatísticas multivariadas que levem em conta a interação natural existente nas diversas variáveis em que se apoiam os conceitos relativos ao risco de crédito, o que pode contribuir para um melhor desempenho do setor financeiro e do sistema produtivo.

Sintetizando os resultados encontrados para as empresas pesquisadas, foram identificados os seguintes fatores como condicionantes da inadimplência: 1) uma empresa de pequeno porte tem maior probabilidade de ser inadimplente, quando comparada com uma microempresa; 2) empresas que atuam em mercados crescentes ou estáveis têm menor chance de estarem inadimplentes; 3) empresas industriais têm maior probabilidade de inadimplência, quando comparada com as comerciais e de serviços; 4) quanto maior o tempo de atividade da empresa, menor a sua propensão à inadimplência; 5) empresas com um nível de informatização intermediário e gerenciadas por sócios possuidores do diploma de segundo grau têm mais chances de serem inadimplentes; 6) quanto maior for o valor dos bens do avalista, menor será a inadimplência no Programa; 7) empresas com sócios com maior tempo de atuação no negócio (experiência na empresa), têm as chances de inadimplência reduzida; 8) quanto maior o uso dos recursos obtidos no financiamento como capital de giro, maior é a probabilidade de inadimplência; 9) quanto maior o faturamento da empresa, menor será sua inadimplência.

Como implicação prática deste trabalho espera-se que os resultados aqui encontrados contribuam para maior compreensão do segmento das MPE's, de maneira a ajudar a entender além das causas, como e por que ainda prevalecem estatísticas negativas neste segmento no contexto brasileiro, na perspectiva de as atenuar ou dirimi-las da forma como deveriam por órgãos e entidades de fomento ao empreendedorismo. Destaque-se que a pesquisa cumpriu com seus propósitos de identificar os fatores que influenciam a inadimplência no âmbito do programa estudado, encontrando resultados relevantes que podem ser utilizados gerencialmente, para traçar políticas ou estratégias por parte da instituição pesquisada e outras correlatas na redução ou controle do seu nível de inadimplência, pela inclusão ou reforço dessas características nos instrumentos de solicitação de crédito.

\section{Artigo recebido em 15.07.2008. Aprovado em 27.01.2009.}




\section{REFERÊNCIAS BIBLIOGRÁFICAS}

Almeida, M. R., \& Ross, E. S. (2000, setembro). A visão dos bancos em relação aos micro e pequenos empresários. Anais do Encontro Nacional da Associação Nacional de Pós-Graduação e Pesquisa em Administração, Florianópolis, SC, Brasil, 24.

Audretsch, B. D. (1999). Small firms and efficiency. In Z. J. Acs (Ed.), Are small firms important? Their role and impact. Washington, DC: U. S. Small Business Administration.

Baumgartner, R. (2004). Propostas para implantação de um sistema de garantia de crédito mutualista como alternativa de acessos ao crédito para as micro, pequenas e médias empresas no Brasil. Dissertação de mestrado, Universidade Federal de Santa Catarina, Florianópolis, SC, Brasil.

Berni, M. (1999). Operação e concessão de crédito: os parâmetros para a decisão de crédito. São Paulo: Atlas.

Bertucci, L. A., Guimarães, J. B., \& Bressan, V. G. F. (2003, setembro). Condicionantes de adimplência em processos de concessão de crédito a micro e pequenas empresas. Anais do Encontro Nacional da Associação Nacional de Pós-Graduação e Pesquisa em Administração, Atibaia, SP, Brasil, 27.

Blatt, A. (1998). Dicas para conceder crédito com menos risco. São Paulo: Nobel.

Caouette, J., Altman, E., \& Narayanan, P. (1998). Managing credit risk: the next great financial challenge. New York: John Wiley \& Sons, Inc.

Casarotto, N., Filho, \& Pires, L. H. (1998) Redes de pequenas e médias empresas e desenvolvimento local. São Paulo: Atlas.

Cia, J. C. (2003, setembro). Propostas de medidas de inadimplência para o mercado brasileiro. Anais do Encontro Nacional da Associação Nacional de Pós-Graduação e Pesquisa em Administração, Atibaia, SP, Brasil, 27.

Douat, J. C. (1994). Desenvolvimento de modelo para administração de carteiras de crédito a pessoas jurídicas em um banco comercial com base na teoria da diversificação de riscos. Tese de doutorado, Fundação Getúlio Vargas, São Paulo, SP, Brasil.

Evans, D. S. (1987). The relationship between firm growth, size and age: estimates for 100 manufacturing industries. The Journal of Industrial Economics, 35(4), 567-581.

Faria, M. P. C. (2006). Análise de crédito à pequena empresa: um modelo de escoragem baseado nas metodologias estatísticas: análise fatorial e lógica fuzzy. Dissertação de mestrado, Instituto Brasileiro do Mercado de Capitais, Rio de Janeiro, RJ, Brasil.

Gil, A. C. (2002). Como elaborar projetos de pesquisa (4a ed.). São Paulo: Atlas.

Gonçalves, G. M. S., Pessoa, E., \& Moreira, M. F. (2007). Causas de falências de micro e pequenas empresas nos primeiros anos de atividade: um estudo exploratório. Anais do Encontro Anual da Associação de Cursos de Graduação em Administração, Cuiabá, MT, Brasil, 18.

Guimarães, J. B. (2002). Financiamento de micros e pequenas empresas em uma instituição pública de crédito. Dissertação de mestrado, Pontifícia Universidade Católica de Minas Gerais, Belo Horizonte, MG, Brasil. 
Horta, R. A. M., \& Carvalho, F. A. (2002, setembro). Um modelo de duas etapas para previsão de insolvência com base em indicadores contábeis. Anais do Encontro Nacional da Associação Nacional de Pós-Graduação e Pesquisa em Administração, Salvador, BA, Brasil, 26.

Marques, L. F. B., \& Kloeckner, G. O. (2002, setembro). Gerenciamento do risco de crédito: um modelo de mercado vs. normas do Banco Central do Brasil. Anais do Encontro Nacional da Associação Nacional de Pós-Graduação e Pesquisa em Administração, Salvador, BA, Brasil, 26.

Minussi, J. A., Damacena, C., \& Ness, W. L., Jr. (2001, setembro). Um modelo preditivo de solvência utilizando regressão logística. Anais do Encontro Nacional da Associação Nacional de PósGraduação e Pesquisa em Administração, Campinas, SP, Brasil, 25.

Naisbitt, J. (1994). Paradoxo global: quanto maior for a economia mundial, mais poderosos são os seus protagonistas menores: nações, empresas e indivíduos. Rio de Janeiro: Campus.

Nucci, A. R. (1999). The demography of business closing. Small Business Economics, 12(1), 25-39.

Oliveira, P. A. S., Najberg, S., \& Puga, F. P. (2000). Sobrevivência das firmas no Brasil: Dez. 1995/Dez. 1997. Revista do BNDES, 7(13), 33-48.

Pandeló, D. R., Jr. (2000, setembro). Avaliação de riscos de instituições financeiras com base em dados contábeis. Anais do Encontro Nacional da Associação Nacional de Pós-Graduação e Pesquisa em Administração, Florianópolis, SC, Brasil, 24.

Sachs, I. (2003). Inclusão social pelo trabalho. Rio de Janeiro: Garamond.

Santos, S. A. (1995). Criando seu próprio negócio: como desenvolver o potencial empreendedor. Brasília: Sebrae.

Schrickel, W. (1997). Análise de crédito: concessão e gerência de empréstimos. São Paulo: Atlas.

Serviço Brasileiro de Apoio às Micro e Pequenas Empresas. (2000). Fatores intervenientes no desempenho econômico-financeiro das micro e pequenas empresas. Recuperado em 30 maio, 2007, de http://www.biblioteca.sebrae.com.br/bte/bte.nsf

Serviço Brasileiro de Apoio às Micro e Pequenas Empresas. (2004). Fatores condicionantes e taxa de mortalidade de empresas no Brasil. Recuperado em 25 maio, 2007, de http://www.wdigital.com.br/mba/estrategia/relatorio_pesquisa_mortalidade_minas.pdf

Serviço Brasileiro de Apoio às Micro e Pequenas Empresas. (2007). Sobrevivência e mortalidade das MPE's constituídas no período 2003 a 2005. Recuperado em 15 outubro, 2007, de http://www.biblioteca.sebrae.com.br/bds/BDS.nsf/8F5BDE79736CB99483257447006CBAD3/ \$File/NT00037936.pdf

Shapero, A., \& Sokol, L. (1982). The social dimensions of entrepreneurship. In C. A. Kent, D. Sexton, \& K. H. Vesper (Eds.), Encyclopedia of entrepreneurship (pp. 72-90). New Jersey: Prentice Hall.

Solomon, S. (1986). A grande importância da pequena empresa. Rio de Janeiro: Nórdica. 